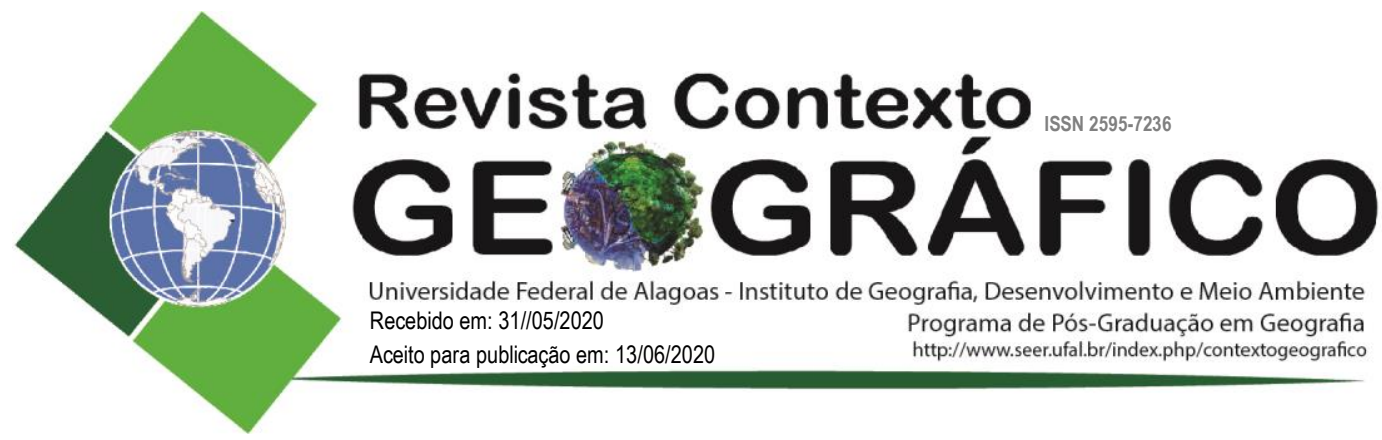

\title{
MAPA ÍNDICE DE VULNERABILIDADE SOCIAL AO COVID-19 NO MUNICÍPIO DE PAULISTA-PE: UM ENSAIO METODOLÓGICO
}

\author{
Diogo Cavalcanti Galvão \\ Professor da Universidade Tiradentes (UNIT), ESUDA, PE, Brasil \\ diogo.esuda@gmail.com \\ Luan Melo \\ Coletivo Popular de Direitos Humanos, PE, Brasil \\ $\underline{\text { luanmelo@gmail.com }}$
}

\begin{abstract}
RESUMO - A partir da demanda de movimentos sociais do município de Paulista, foi elaborado um mapa síntese de vulnerabilidade da cidade em relação a crise sanitária e de saúde pelo COVID-19. Sendo assim, este artigo traz um ensaio metodológico empregando a técnica de AHP. O município é integrante da Região Metropolitana do Recife, seu histórico de ocupação, bem como sua estrutura física faz com que surjam aglomerados vulneráveis socioambientais. O produto gerado teve satisfatória aceitação pelo poder público e principalmente pelos munícipes, que a partir dele identificaram áreas prioritárias para atuação de ações solidárias. Apesar deste aspecto positivo, por ter um caráter de ensaio, o mapa estará à mercê de apontamentos para seu aprimoramento.
\end{abstract}

Palavras-chave: Vulnerabilidade; COVID-19; AHP.

\section{SOCIAL VULNERABILITY INDEX MAP TO COVID-19 IN THE MUNICIPALITY OF PAULISTA-PE: A METHODOLOGICAL TEST}

\begin{abstract}
Based on the demand for social movements in the municipality of Paulista, a synthesis map of the city's vulnerability in relation to the sanitary and health crisis was prepared by COVID-19. Thus, this article brings a methodological essay using the AHP technique. The municipality is part of the Metropolitan Region of Recife, its history of occupation, as well as its physical structure causes vulnerable socio-environmental clusters to emerge. The generated product was satisfactorily accepted by the public authorities and mainly by the citizens, who from it identified priority areas for action of solidarity actions. Despite this positive aspect, as it has a test character, the map will be at the mercy of notes for its improvement.
\end{abstract}

Keywords: Vulnerability; COVID-19; AHP.

\section{INTRODUÇÃO}

O Presente artigo é parte inicial de um monitoramento popular em relação ao comportamento da epidemia do coronavírus no município de Paulista do norte metropolitano do Recife, visando contribuir com a construção de um conhecimento implicado na realidade que auxilia iniciativas para a contenção dos possíveis impactos da crise sanitária e de saúde, sobretudo nas áreas mais vulneráveis da cidade. Apesar da contaminação pelo coronavírus não distinguir renda, gênero ou raça, as desigualdades estruturais abissais das cidades brasileiras, constituem um condicionante a mais na capacidade de prevenção, tratamento e de lidar com as consequências pós pandêmicas. 
Por se tratar de uma crise ainda em curso e com pouca bibliografia de referência que possa auxiliar na elaboração diretrizes e ações estratégicas na contenção da disseminação do vírus nos espaços urbanos tão heterogêneos como os das cidades brasileiras, aqui assume-se o caráter de ensaio metodológico do mapeamento de vulnerabilidade ao COVID-19.

Logo, o objetivo deste artigo é apresentar o método de mapeamento de vulnerabilidade no contexto da pandemia do novo coronavírus no município de paulista-PE, a partir do uso do processo de análise hierárquica (AHP). Apesar da área de estudo ser escolhida por demanda de movimentos sociais do município, é imperativo indicar que a área em escopo tem caráter bastante representativa daquelas que são periféricas, mesmo fazendo parte de uma região metropolitana. Portanto, há possibilidade de reaplicar este método, para outras localidades ajustando-se apenas algumas variáveis peculiares a cada realidade.

Esse trabalho será estruturado num primeiro momento, através de uma pequena análise das nuances quanto ao conceito de vulnerabilidade, uma vez que sugerimos aqui uma nova vulnerabilidade, que apesar de transitória terá 2 tempos. O presente, em relação às ações que o poder público deve tomar para frear a contaminação, e o futuro, criando áreas de monitoramento para abrandar os impactos sociais pós-pandemia.

Após esta breve análise, focaremos nas apresentações das variáveis e da estrutura lógica da construção das hierarquias e pesos do método AHP, para enfim reproduzir o mapeamento de vulnerabilidades. E por ter um caráter participativo, as discussões dos resultados tiveram contribuições dos movimentos sociais para identificação de calibração do que encontramos como áreas mais vulneráveis ao COVID.

\section{DISCUTINDO A VULNERABILIDADE}

Para este trabalho, é necessário se debruçar sobre o conceito de vulnerabilidade, e nessa direção precisa-se delinear o entendimento sobre tal, visto que não existe um único sentido para essa expressão, que já está em disputa semântica. Preliminarmente é fundamental ter o discernimento de que, seja como for, o conceito é utilizado a partir de noções políticas, mesmo quando não declaradas, por atores e em contextos distintos (BRANDÃO, 2002).

Com o objetivo de melhor compreender as questões em torno do conceito de vulnerabilidade, ampara-se partir da leitura para a formulação do entendimento do Instituto de Pesquisa Econômica Aplicada - IPEA, na formulação do Índice de Vulnerabilidade Social - IVS, que numa revisão bibliográfica sintetizada, nos destaca duas noções que ganham notoriedade acerca da vulnerabilidade, sendo a primeira o entendimento de Robert Castel (1998), que cunha a noção de vulnerabilidade à desfiliação; e o segundo colocado por Caroline Moser (1998), que reflete na perspectiva de uma vulnerabilidade de ativos em um escrito para o Banco Mundial.

Castel (1998), investiga a inserção do sujeito à estrutura da sociedade, que para ele acontece em dois âmbitos, o do acesso ao trabalho e o das relações de proximidade, classificando ambos de forma distinta em uma escala de três níveis.

A escala de classificação da inserção do sujeito pelo acesso ao trabalho, acontece nos seguintes níveis: o do trabalho estável (com garantias trabalhistas e sem data prevista para o fim), o do trabalho precário (trabalhos de contrato temporário, ou trabalhos sem contrato que não oferecem segurança de direitos trabalhistas ao contratado) e o da não inserção (pessoas com incapacidade de trabalhar ou pessoas desempregadas).

No tocante as chamadas relações de proximidade, os três níveis da classificação de Castel são os seguintes: Fortes (quando o sujeito desfruta de uma base familiar segura e ou de amizades e parceiros estáveis), frágeis (quando o sujeito tem relações familiares frágeis e ou redes de amizade frágeis e ainda parcerias instáveis e inseguras), e existiria ainda as pessoas sem inserção de relações de proximidade (que vivenciam o isolamento social, como pessoas em situação de rua). 
Com a junção das duas categorias de inserção do sujeito às dinâmicas sociais, levando em consideração os níveis pensados para cada situação, o autor chega a três Zonas de inserção social do sujeito (TABELA 01), sendo elas: a zona de inserção (que mescla uma inserção social pelo trabalho forte com uma inserção por relações de proximidade estáveis), a zona de desfiliação (que seria exatamente o contrário da primeira, onde o sujeito nem tem inserção social pelo trabalho, nem por relações de proximidade), a zona que estaria no meio dos extremos apontados seria a zona de vulnerabilidade (onde o sujeito tem uma inserção social pelo trabalho precária e de relações de proximidade frágeis).

Quadro 1. Zonas sociais de inserção

\begin{tabular}{|c|c|c|c|}
\hline $\begin{array}{c}\text { MUNDO DO } \\
\text { TRABALHO }\end{array}$ & Trabalho Estável & Trabalho Precário & Não Trabalho \\
\hline ZONAS SOCIAIS & Integração & Vulnerabilidade & Desfiliação \\
\hline $\begin{array}{c}\text { RELAÇÕES DE } \\
\text { PROXIMIDADE }\end{array}$ & Fortes & Fracas & Isolamento \\
\hline
\end{tabular}

Fonte: Castel, 1998. Elaboração: Os autores

O autor então mobiliza o conceito de "vulnerabilidade social", para se referir a condição dos sujeitos que estariam entre a integração total nas dinâmicas sociais e os sujeitos que experimentam a desfiliação social. Apesar do modelo analítico proposto, Castel (1998), afirma que o sujeito pode transitar por várias das categorias, durante sua vida e que a classificação deve ser sensível às oscilações possíveis.

O sujeito que se encontra na zona de vulnerabilidade, tem sua qualidade de vida dependente de condicionantes que podem provocar instabilidades, com o desemprego, acidentes, enfermidades, invalidez e outros imprevistos.

Uma questão central é a dimensão coletiva em relação ao risco social no qual, o trabalhador que depende do salário para manter-se, está condicionado. Como a análise de Castel se dá a partir da sociedade industrial, da análise do mundo do trabalho, acabou por influenciar as noções de seguridade social, onde o trabalhador desprovido de salário deveria receber a solidariedade do estado e de toda a sociedade do trabalho.

Já para a segunda noção mais difundida sobre a conceituação da vulnerabilidade, cunhada por Caroline Moser (1998), que seria a vulnerabilidade de ativos, desenvolvida a partir da investigação acerca dos processos de pobreza nas sociedades perimetrais. A autora chega ao entendimento de que o não acesso a ativos simbólicos ou materiais, e a inabilidade na gestão dos recursos disponíveis diante de situações de risco, as quais a população pobre está submetida, são as causas do mal-estar social.

O risco em Moser, tem uma noção distante do risco social evocado por Castel, se aproximando de outras categorias de risco, como os riscos ambientais, sanitários, riscos a catástrofes naturais, riscos alimentares, políticos, dentre outros. Baseado nesse entendimento a vulnerabilidade de ativos, seria composta pelas dimensões do não acesso e manipulação inadequada de ativos. Sendo assim, para combater esta vulnerabilidade devem ser tomadas medidas para o fornecimento de ativos e condições para uma melhor manipulação destes.

As ideias de Moser foram desenvolvidas por outros pesquisadores associados ao Banco Mundial e tem influenciado políticas baseadas na visão de que as vulnerabilidades estão no déficit inerente aos sujeitos, diferente do proposto por Castel, que vê a origem da vulnerabilidade na estruturação da sociedade capitalista.

Diante das duas perspectivas hegemônicas da disputa do entendimento da vulnerabilidade colocadas, o IPEA busca mesclar elementos chaves contidos em cada um dos conceitos para 
definir a perspectiva de vulnerabilidade do IVS. De Castel, a noção de que a vulnerabilidade e os riscos sociais são fruto de questões estruturais da sociedade e por isso o indivíduo por si só não possui as condições de superá-la, precisando de uma ação do estado nos seus três níveis, federal, estadual e municipal, com a estruturação de políticas públicas. Porém o IVS, não se propõe a investigar a vulnerabilidade a partir da inserção do sujeito à sociedade pelas relações de proximidade, como proposto pelo autor. Já em Moser, a noção de que ativos influenciam no bem-estar do sujeito está colocada.

O IVS enquanto instrumento, foi pensado para ser uma ferramenta na elaboração de políticas públicas, atestando a ausência de ativos que de acordo com a Constituição Federal (1988) deveriam ser oferecidos pelo estado a todo cidadão.

Como nosso objetivo através deste trabalho é traçar uma prioridade na tomada de decisões a partir da identificação das áreas mais vulneráveis no contexto da pandemia do novo coronavírus, além do IVS, que é composto a partir do cruzamento de 16 indicadores, extraídos do censo demográfico do IBGE (2010), distribuídos em três dimensões, sendo elas: Dimensão Infraestrutura Urbana (coleta de lixo, água e esgoto inadequado e tempo de deslocamento casatrabalho), Dimensão Capital Humano (mortalidade infantil, crianças de 0 a 5 anos fora da escola, pessoas de baixa renda que não estudam e não trabalham, crianças entre 6 e 14 anos fora da escola, mães jovens entre 10 e 17 anos, mães sem fundamental com filhos de até 15 anos, analfabetismo, crianças em domicílio em que ninguém tem o ensino fundamental completo) e Dimensão Renda e Trabalho (pessoas com renda menor ou igual a $\mathrm{R} \$ 255$, Pessoas de baixa renda dependentes de idosos, desocupados, trabalho infantil, ocupação informal sem ensino fundamental), vamos utilizar também outros indicadores, que são fundamentais para o cumprimento das recomendações das autoridade de saúde na contenção do avanço da pandemia.

\section{MATÉRIAIS E MÉTODOS}

\section{O Município de Paulista}

Com fundação datada de 1935, quando ganhou autonomia em relação ao município de Olinda, o município de Paulista, no Polo Norte da Região Metropolitana do Recife (ver mapa 1), tem uma história que vem desde os primeiros anos da colonização portuguesa no Brasil, tendo seu território ocupado por grandes engenhos de cana-de-açúcar. Durante o século $\mathrm{XX}$, a cidade foi um importante polo industrial do estado de Pernambuco, com a transformação de antigos engenhos em complexos fabris têxteis e vilas operárias. Hoje em dia, a economia da cidade além do resquício da atividade industrial, se destaca pelas atividades de comércio, serviço e turismo.

Segundo o censo demográfico (IBGE, 2010), Paulista tinha uma população de 300.466 pessoas, tendo uma população estimada em 2019 de 331.774 pessoas, distribuídas em uma área de 96, $979 \mathrm{~km}^{2}$. O município se desenvolve num terreno cujo relevo é caracterizado predominantemente pela ocorrência de tabuleiros com alturas variando de 40 a 50 metros próximo a zona costeira e 160 metros na parte oeste da cidade. A presença de elementos naturais é muito forte na paisagem de Paulista, que possui grande parte de sua área ocupada por remanescentes da mata atlântica como as da Jaguarana, Caetés e do Janga. Outro elemento natural importante é o rio Paratibe, que nasce na zona rural do município no extremo oeste e deságua a leste no oceano Atlântico.

Esses resquícios florestais são atualmente pressionados por uma expansão urbana primordialmente espontânea e/ou com poucas restrições urbanísticas, quando produzida de maneira "legal" (OLIVEIRA, 2015). Já para as ocupações em áreas ribeirinhas, ainda segundo Oliveira (2015), o Município do Paulista encontra-se inserido nas bacias hidrográficas do rio Paratibe e do rio Timbó, em micro bacias litorâneas e numa pequena parcela da bacia 
hidrográfica do rio Igarassu. O rio Paratibe, o principal rio do município, também é protagonista quanto as ocupações ribeirinhas, ocasionando agravos socioambientais. Essas configurações urbano/ambientais culmina em distorções sociais importantes para a análise deste artigo.

Figura 1. Mapa de localização regional e índice de desenvolvimento humano de Paulista

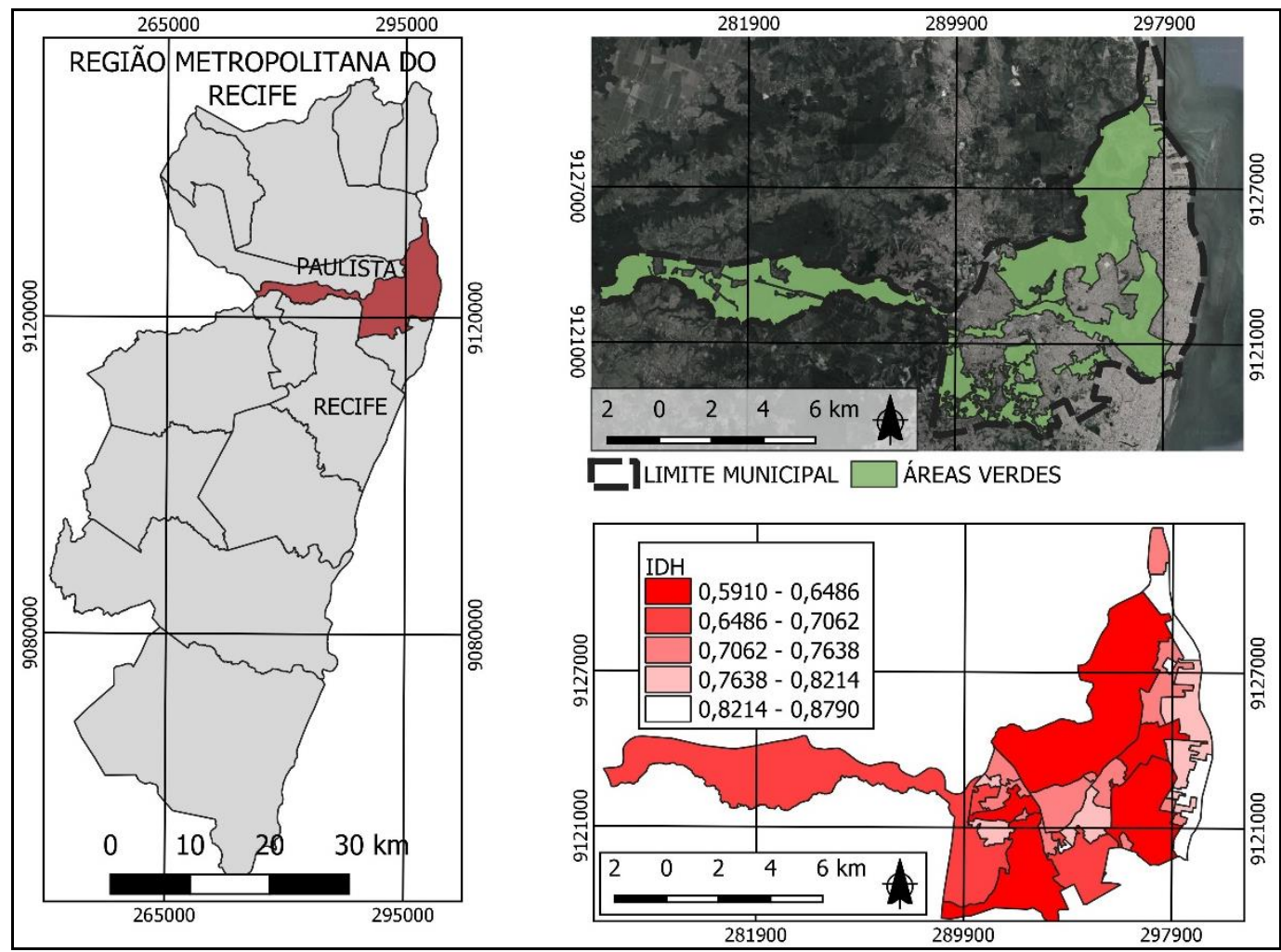

Org. Autores (2020)

Ainda em 2010, o Índice de Desenvolvimento Humano (IDH) para o município, correspondia a pontuação de 0,732 , acima da média estadual, o que representa a quarta posição entre as cidades pernambucanas. Apesar do bom desempenho no IDH, uma análise intra urbana no município pode revelar desigualdades abissais. Enquanto a frente atlântica concentra uma população que desfruta das melhores qualidades de vida no município, existem muitos territórios na periferia das áreas urbanizadas da cidade, nos interstícios urbanos de interface com o meio natural, com concentração de pobreza, áreas vulnerabilizadas, localizadas em terras de baixo valor econômico e grande risco ambiental, como as comunidades ao longo da várzea do rio Paratibe, ou nos limites do Parque do Janga, um importante manguezal urbano.

O censo do IBGE em 2010, nos traz também informações sobre questões de infraestrutura do município, como o esgotamento sanitário, que na época representava um total de $60,8 \%$ de cobertura nos assentamentos humanos do município, o que seria um bom resultado se comparado a outras cidades de Pernambuco. Em relação ao quesito trabalho e renda, o IBGE em 2017, afirma que 35.411 pessoas no município possuem uma ocupação, o que representa $10,8 \%$ da população total. A média mensal do salário de trabalhadores formais residentes no município é de dois salários mínimos.

\section{CONSTRUÇÃO METODOLÓGICA}

A elaboração do mapa síntese da vulnerabilidade aos impactos suscitados pelo COVID-19, é 
precedida pela execução de alguns mapas intermediários com conteúdo hierarquicamente estabelecidos. Para a confecção do produto principal, foram escolhidos critérios de importância ímpar na resiliência urbana tanto durante a pandemia, quanto para o pós-pandemia. As escolhas das variáveis se deu a partir de reuniões temáticas entre sociólogos, arquitetos e urbanistas e geógrafos. No primeiro momento foram elencados elementos que podem auxiliar ou dificultar o combate contra o vírus, logo, a utilização de dados sociais de renda, faixa etária e estrutura familiar sugeririam qual o perfil da família que mais sofreria com perda de renda e os desafios de manter condições mínimas de sustento. As variáveis infra-estruturais apontam para os serviços básicos de saneamento, bem como da estrutura residencial, ambos indicando a possibilidade de higienização e confinamento em casos suspeitos na família e variáveis ambientais, que preconizou a identificação de áreas que poderiam sofrer transtornos de cunho climático, nos períodos de chuva (maio a agosto), e que necessitariam de remoção e alojamento em massa das áreas de risco a deslizamento ou enchentes.

As produções cartográficas foram realizadas a partir do software livre QGIS 3.6, por se tratar de um mapeamento municipal, a escala trabalhada foi de $1 / 85.000$, possibilitando a ilustração de todo o território.

Os dados utilizados para este estudo tiveram duas origens, a primeira se deu por fontes oficiais como IBGE (2010), IPEA (2015), Prefeitura municipal de Paulista (2013), CONDEPE/FIDEM (2010) e imagens de satélite de alta resolução. Já na segunda fonte, foram priorizadas as informações territoriais advindas dos movimentos e associações parceiras, enfatizando o conhecimento da realidade local, vinda dos próprios moradores. Houve a necessidade de correção/atualização de alguns dados, uma vez que a temporalidade dos dados, como já foi discutido, é muito defasada.

\section{Quanto aos dados sociais}

O primeiro condicionante utilizado para o mapeamento foi o IVS - Índice de Vulnerabilidade Social, contido no Atlas da Vulnerabilidade Social nos Municípios e Regiões Metropolitanas Brasileiras, desenvolvido pelo Ipea - Instituto de Pesquisa Econômica Aplicada, em 2016, um estudo que se debruça sobre a realidade da unidade político-administrativa mais próxima do cotidiano das pessoas: o município.

Outra variável analisada foi a de Densidade demográfica, este condicionante expressa o total de habitantes por setor censitário, dividido pela área em hectares, ou seja, as concentrações de pessoas em cada fragmento. É uma informação importante a ser observada no contexto da corrente pandemia, pois uma das recomendações para se evitar a contaminação acelerada da população é o isolamento social, sendo as áreas mais densas, ambientes mais propícios à propagação do vírus, pela alta concentração de pessoas. Esta variável será novamente chamada, para indicar como em conjunto com outras variáveis, traz um cenário preocupante para a pandemia.

Focando no grupo de risco em caso de infecção do COVID - 19, a presença de pessoas com 60 anos ou mais por setor censitário (\%) foi elaborada a partir dos dados censitários do IBGE (2010). Por apresentar um lapso temporal de 10 anos, foram realizados ajustes na confecção dos subgrupos de faixa etária. Utilizou-se faixas a partir de 50 anos (estimadas em 2010), acrescentando-se 10 anos e para a faixa etária final, utilizou-se o fator de redução do IDHM Longevidade indicado também pela expectativa de vida ao nascer, estimada para unidades de desenvolvimento humano das mesmas áreas. Por fim, calculou-se o percentual de idosos em relação ao total de residentes em cada setor censitário, buscando áreas de maior concentração percentual de idoso.

Já a presença de famílias dependentes da renda do idoso segundo o IBGE (2010), revela a razão entre as pessoas que vivem em domicílios vulneráveis à pobreza (com renda per capita inferior a 1/2 salário mínimo de agosto de 2010) e nos quais a maior parte da renda provém de moradores com 65 anos ou mais de idade e população total residente em domicílios particulares 
permanentes, multiplicada por 100. Este dado é fundamental para analisarmos as consequências pós-pandêmicas, visto que a população idosa com 60 anos ou mais, foi considerada pela OMS como sendo a de maior taxa de mortalidade observada, diante da infecção pelo novo coronavírus, sendo assim, famílias que perderem o ente que é o seu arrimo estariam em situação de desamparo. Esta variável, apesar de tratar de idosos, não necessitou de ajuste temporal, uma vez que a condição atual de renda e trabalho vem apontando para a precarização e diminuição dos trabalhos formais, reforçando a dependência da renda fixa oriunda de aposentadorias e benefícios destinados aos idosos.

Quanto a mães chefes de família, indicando as famílias monoparentais femininas - aquela onde convive a mulher e seus filhos sendo a mulher a provedora - é cada vez maior. Dados do último censo realizado pelo IBGE e publicados em 2012 dão conta de que este formato de família convivente representava em 2010, 53,5\% dos arranjos familiares no país.

Nos estudos de cunho social, faz-se necessário levar em consideração a determinação da raça (\%) no processo de análise da realidade. Falar em raça no Brasil é muito relevante, já que a formação social deste país é marcada por períodos de extrema violência a grupos específicos. Esta relevância se configura como uma premissa também de um agente produtor do espaço urbano, principalmente na formação das periferias.

\section{Quanto aos dados infraestruturais urbanos}

O abastecimento d'água foi criado a partir dos dados georreferenciados das áreas atendidas por redes e terminais de abastecimento oficiais, excluindo-se os poços artesianos por não ter esta informação de forma oficial ou confiável. Este quesito foi escolhido de acordo com as recomendações da OMS (2020), que indica a necessidade constante de higienização dos ocupantes de imóveis. Áreas sem conexão à rede de abastecimento foram classificadas com maiores pesos, para o cálculo posterior de vulnerabilidade.

$\mathrm{O}$ mesmo aconteceu com a rede de esgotamento sanitário, o saneamento básico é um elemento norteador para a amenização de arboviroses e Doenças Relacionadas ao Saneamento Ambiental Inadequado (DRSAI), o que poderia proporcionar baixa na imunidade da população residente em áreas com déficit desta infraestrutura.

As áreas precarizadas, são o somatório dos Aglomerados Subnormais (IBGE, 2010) das áreas demarcadas como Zonas Especiais de Interesse Social (ZEIS) no Zoneamento Urbano Municipal (PAULISTA, 2013) e áreas que foram indicadas por integrantes da Rede COPPA (Coletivos Populares de Paulista), que se enquadraram no perfil das duas referências anteriores, mas que não estavam mapeadas, provavelmente por questões de distanciamento temporal.

Segundo o IBGE (2010), Aglomerados Subnormais podem ser entendido como uma forma de ocupação irregular de terrenos de propriedade alheia - públicos ou privados - para fins de habitação em áreas urbanas e, em geral, caracterizados por um padrão urbanístico irregular, carência de serviços públicos essenciais e localização em áreas restritas à ocupação. Já ZEIS são áreas de assentamentos habitacionais de população de baixa renda, surgidos espontaneamente, existentes, consolidados ou propostos pelo poder público, onde haja possibilidade de urbanização e regularização fundiária (PAULISTA, 2013).

Quanto as habitações, segundo o IBGE em 2010, o indicativo de percentual de domicílios com densidade superior a duas pessoas por dormitório, expressa a razão entre a população que vive em domicílios particulares permanentes com densidade superior a 2 e a população total residente em domicílios particulares permanentes, multiplicada por 100. A densidade do domicílio é dada pela razão entre o total de moradores do domicílio e o número total de cômodos usados como dormitório.

É nesse sentido que o indicador interessa para definição das áreas de maior vulnerabilidade no contexto da pandemia do Novo COVID. Como é de conhecimento amplo e indicado pela OMS (2020), o isolamento social é uma das principais recomendações para o controle do ritmo de 
contágio da população, evitando a sobrecarga do sistema de saúde, o que se torna inviável em moradias com densidades altas de moradores em relação aos cômodos.

\section{Quanto aos dados ambientais}

As áreas de risco do município de Paulista foram mapeadas pela Agência Estadual de Planejamento e Pesquisas de Pernambuco - CONDEPE/FIDEM em 2010, no Plano Metropolitano de Redução de Risco - PMRR. O mapeamento engloba áreas com risco de deslizamentos, distribuídas numa escala que parte do baixo risco, passando pelo médio risco, chegando ao risco alto e muito alto. O mapeamento da FIDEM, também aponta as áreas com risco de alagamento, que em Paulista não passam do risco baixo.

Já as áreas verdes foram mapeadas afim de identificar áreas de amenização dos dados de ausência de infraestrutura (água e esgoto), bem como áreas de densidade demográfica, uma vez que os setores censitários (unidades espaciais) englobam áreas ocupadas ou não.

\section{PROCESSO ANALÍTICO HIERÁRQUICO (AHP)}

O método escolhido para a elaboração do mapa síntese foi a AHP de Saaty (1991), onde a análise hierárquica busca reduzir o estudo de sistemas a uma sequência de comparações aos pares. Esta forma de organização é semelhante ao método natural de funcionamento da mente humana, onde ao se deparar a um grande número de elementos, a mente compartimenta em grupos segundo prioridades comuns (SILVA, 2007). Segundo este autor p. 37 " O cérebro repete esse processo e agrupa novamente os elementos em outro nível "mais elevado", em função de propriedades comuns existentes nos grupos de nível imediatamente abaixo".

A abordagem da AHP foca na divisão do problema central em avaliações de variáveis de menor importância, mas mantendo todos os níveis destas variáveis na decisão global. De tal modo, cada uma destas variáveis deve sofrer uma análise comparativa de forma pareada, fomentando a criação de valores que proporciona a hierarquização matemática das relações entre si.

Assim, a escolha do método AHP foca nesta hierarquia imparcial com a avaliação par a par (variável por variável), o que impõe certa equalização de agrupamento dos valores "intravariável". Uma vez que se utilizou dados com unidades de medidas bastante distintas entre si, demográficos (hab/hec), percentual, índices sociais, entre outros. Tomou-se como técnica a criação de subgrupos para cada variável, buscando sempre limitar ao máximo de 5 pesos (1-2-34-5), em casos de variável com apenas 3 subgrupos foram atribuídos valores intercalados (1-35) e para variáveis binárias, valores de (1-5), verificar tabela 1.

Tabela 1. Organização de pesos entre atributos

\begin{tabular}{lccc}
\hline \multicolumn{1}{c}{ Variável } & $\begin{array}{c}\text { Critério de } \\
\text { divisão }\end{array}$ & Subgrupos \\
\hline $\begin{array}{l}\text { IVS - Índice de Vulnerabilidade Social; } \\
\text { Densidade demográfica; pessoas com 60 } \\
\text { anos ou mais por setor censitário; Família } \\
\text { dependente de renda do idoso; mães chefes } \\
\text { de família; Raça; Densidade de pessoas por } \\
\text { dormitório }\end{array}$ & $\begin{array}{c}\text { Quebras } \\
\text { naturais } \\
\text { (jenks) }\end{array}$ & 1 à 5 \\
\hline $\begin{array}{l}\text { Abastecimento d'água; Serviço de } \\
\text { esgotamento sanitário; Áreas precarizadas; } \\
\text { Áreas verde }\end{array}$ & $\begin{array}{c}\text { Binário } \\
\text { (existência) }\end{array}$ & 1 e 5 \\
\hline $\begin{array}{c}\text { Classificação } \\
\text { prévia de } \\
\text { Áreasco de risco }\end{array}$ & 1,3 e 5 \\
\hline
\end{tabular}

Org. Autores (2020) 
No segundo momento, após definição das variáveis, cria-se uma matriz estruturada por estas variáveis, possibilitando a comparação par a par, utilizando uma base de escala de importância com valores entre 1 a 9, como pode ser visto na tabela 2 .

Tabela 2. Indicativo de intensidade de importância das variáveis

\begin{tabular}{ccc}
\hline $\begin{array}{c}\text { Intensidade de } \\
\text { Importância }\end{array}$ & Definição & Explicação \\
\hline 1 & Importância Equiparada & $\begin{array}{c}\text { Contribuição equiparada para o } \\
\text { objetivo }\end{array}$ \\
\hline 3 & Importância Moderada & $\begin{array}{c}\text { Um objetivo ligeiramente favorável } \\
\text { em detrimento de outro }\end{array}$ \\
\hline 5 & Importância Forte & $\begin{array}{c}\text { Um objetivo fortemente favorável } \\
\text { em detrimento de outro }\end{array}$ \\
\hline 7 & Importância Muito Forte & $\begin{array}{c}\text { Um objetivo fortemente favorável } \\
\text { em detrimento de outro; domínio } \\
\text { demonstrado na prática }\end{array}$ \\
\hline 9 & Importância Absoluta & $\begin{array}{c}\text { É a maior ordem de afirmação } \\
\text { possível de um objetivo em } \\
\text { detrimento de outro }\end{array}$ \\
\hline $2,4,6,8$ & $\begin{array}{c}\text { Valores intermediários entre } \\
\text { dois julgamentos sucessivos }\end{array}$ & $\begin{array}{c}\text { Possível necessidade de se } \\
\text { interpolar julgamentos numéricos }\end{array}$ \\
\hline & Fonte. Saaty (1991), alterado pelos Autores (2020)
\end{tabular}

Por fim, deve-se criar a média ponderada de todos os atributos e a fim de constatar a consistência destes valores, utiliza-se a equação da razão de coerência, indicada por Saaty (1994), buscando o resultado abaixo de 3\%. Em caso de comprovada a consistência, a análise das variáveis é dada com válida matematicamente.

\section{Quanto ao processo}

As variáveis selecionadas foram especializadas a partir de dados vetoriais retirados ou dos bancos de dados virtuais dos órgãos governamentais (IBGE, CONDEPE, IPEA) ou produzido pelos autores deste presente artigo, seguindo nas suas tabelas de atributos houve a produção e o preenchimento da coluna "VALOR" com os valores de subgrupos, com o intuito de estabelecer os pesos a serem utilizados. Posterior, foi realizada a "rasterização" destes vetores e cada pixel foi abastecido com os valores do campo supracitado.

Por fim, deve-se usar a calculadora raster para criar um raster único a partir das somas de todos os rasters produzidos anteriormente. Esta equação será representada no item de Resultados e discussões, bem como a matriz com os valores de intensidade de importância atribuídos a cada variável na análise par a par.

\section{RESULTADOS E DISCUSSÕES}

A partir da análise prévia de especialistas (apresentados no item anterior) e moradores dos territórios vulneráveis do município e posteriormente a aplicação do método AHP, foram obtidos os pesos referentes a avaliação par a par das variáveis, assim, estabelecendo suas hierarquias, observada na tabela 3.

Tabela 3. Matriz de valores dos autovetores pelo método AHP 


\begin{tabular}{|c|c|c|c|c|c|c|c|c|c|c|c|c|}
\hline & 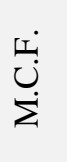 & 苍 & $\sum$ & 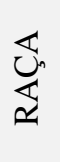 & 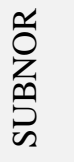 & 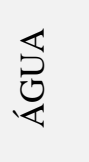 & $\begin{array}{l}0 \\
ٍ \\
0 \\
\mathscr{D} \\
\text { 포 }\end{array}$ & نَ & 走 & ¿ & $\begin{array}{l}\sum_{\text {II }} \\
\dot{\theta}\end{array}$ & $\stackrel{>}{\gtrless}$ \\
\hline M.C.F. & 1 & $1 / 3$ & $1 / 7$ & 5 & $1 / 7$ & $1 / 5$ & $1 / 3$ & 5 & 3 & 1 & $1 / 5$ & $1 / 2$ \\
\hline DOR & 3 & 1 & $1 / 3$ & 7 & $1 / 3$ & $1 / 3$ & 5 & 3 & 3 & 2 & 1 & 1 \\
\hline IVS & 7 & 3 & 1 & 7 & 6 & 3 & 5 & 7 & 4 & 3 & 3 & 3 \\
\hline RAÇA & $1 / 5$ & $1 / 7$ & $1 / 7$ & 1 & $1 / 5$ & $1 / 3$ & $1 / 3$ & $1 / 3$ & $1 / 3$ & $1 / 3$ & $1 / 7$ & $1 / 3$ \\
\hline SUBNOR & 7 & 3 & $1 / 6$ & 5 & 1 & $1 / 2$ & 3 & 5 & 1 & 3 & 3 & 3 \\
\hline ÁGUA & 5 & 3 & $1 / 3$ & 3 & 2 & 1 & 7 & 9 & 9 & 7 & $1 / 3$ & 2 \\
\hline ESGOTO & 3 & $1 / 5$ & $1 / 5$ & 3 & $1 / 3$ & $1 / 7$ & 1 & 3 & $1 / 7$ & $1 / 5$ & $1 / 5$ & $1 / 3$ \\
\hline R.I. & $1 / 5$ & $1 / 3$ & $1 / 7$ & 3 & $1 / 5$ & $1 / 9$ & $1 / 3$ & 1 & $1 / 3$ & $1 / 3$ & $1 / 5$ & $1 / 3$ \\
\hline Á.R & $1 / 3$ & $1 / 3$ & $1 / 4$ & 3 & 1 & $1 / 9$ & 7 & 3 & 1 & $1 / 3$ & $1 / 5$ & 1 \\
\hline $60+$ & 1 & $1 / 2$ & $1 / 3$ & 3 & $1 / 3$ & $1 / 7$ & 5 & 3 & 3 & 1 & $1 / 5$ & $1 / 3$ \\
\hline D. DEM & 5 & 1 & $1 / 3$ & 7 & $1 / 3$ & 3 & 5 & 5 & 5 & 5 & 1 & 2 \\
\hline A.V & 2 & 1 & $1 / 3$ & 3 & $1 / 3$ & $1 / 2$ & 3 & 3 & 1 & 3 & $1 / 2$ & 1 \\
\hline
\end{tabular}

Org. Autores (2020)

Após os cálculos dos valores ponderados, foram realizados os cálculos dos autovetores com 2 intuitos: o primeiro para verificar a consistência das matrizes realizadas, onde obteve-se o resultado abaixo de 2\%, como preconiza o método de Saaty (1977) e o segundo serão responsáveis por determinar o peso que cada variável abastecerá a equação, para definir a vulnerabilidade do município de paulista, quanto aos agravos sociais durante e pós pandemia (TABELA 4).

Tabela 4. Valores finais do método AHP

\begin{tabular}{c|c}
\hline VARIÁ VEL & VALOR \\
\hline M.C.F. & 0,05 \\
\hline Dormitório & 0,09 \\
\hline IVS & 0,23 \\
\hline Raça & 0,02 \\
\hline Aglomerado Subnormal & 0,12 \\
\hline Água & 0,18 \\
\hline Esgoto & 0,04 \\
\hline R. Idoso & 0,02 \\
\hline Área de Risco & 0,06 \\
\hline 60+ & 0,06 \\
\hline Área Verde & 0,05 \\
\hline Densidade Demográfica & 0,08 \\
\hline TOTAL & $\mathbf{1}$ \\
\hline Raz. de Coerência & $\mathbf{0 , 3 4 \%}$ \\
\hline Org. Autores &
\end{tabular}

Org. Autores (2020)

Obtidos então os valores e comprovada a sua consistência metodológica, utilizou-se cada um destes, juntamente com os subgrupos já produzidos no Qgis 3.6, na ação de rasterização dos vetores, para enfim criar uma equação final de soma a partir da calculadora raster, unificando os autovetores em valor único, bem como um raster que representa a soma de todos os outros, como indica a equação, figura 2.

Figura 2. Equação de produção de raster total do município de Paulista e esquema didático de 
produção dos dados espaciais.
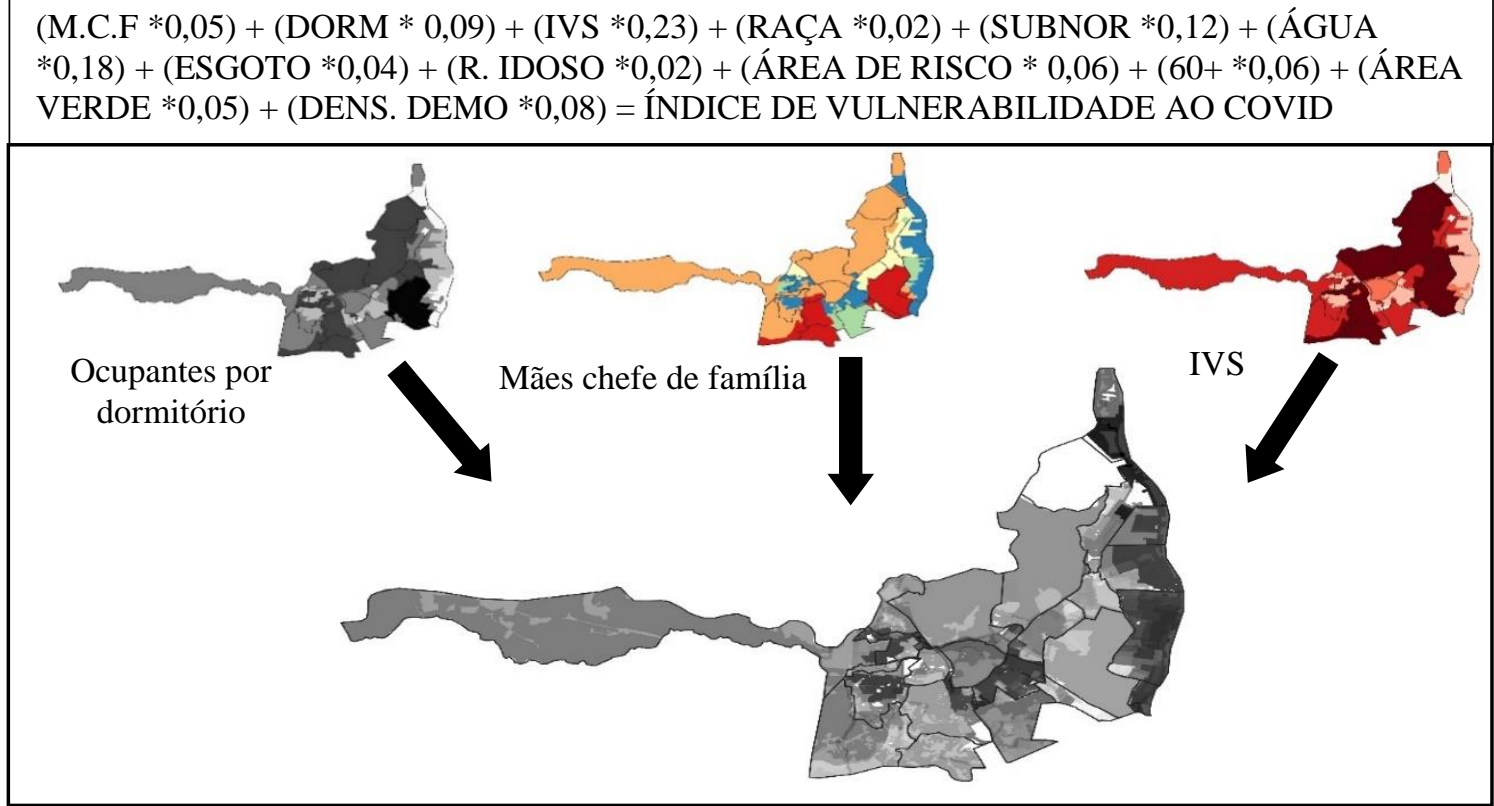

Org. Autores (2020)

Após a execução da soma dos auto vetores na ordem espacial, utilizou-se o método graduado das quebras naturais (JENKS), buscando dar ênfase nas áreas de maior vulnerabilidade. Optouse por manter a ilustração das manchas verdes no mapa síntese, para que pudesse entender a relação das proximidades das áreas vulnerabilizadas e os resquícios de mata, bem como indicar a atenuação da ausência de infraestruturas nas áreas não ocupadas.

Após o término da produção do documento cartográfico, ele foi enviado a rede Coppa, afim de averiguar quanto os dados ora apresentados, estavam de acordo com o reconhecimento territorial dos movimentos sociais componentes do coletivo. É mister indicar a importância emergencial que se passa, as comprovações de vulnerabilidade não poderiam vir apenas dos dados oficiais, já que grande parte deles estavam defasados, mas sim, principalmente devem ser oriundos do reconhecimento cotidiano dos munícipes residentes em áreas precárias e normalmente informais.

Em primeira instância verificou-se que a distribuição das áreas mais vulneráveis do município corrobora para uma já comprovada história de ocupação espontânea periférica da região metropolitana do Recife. Estas, se dão mormente nas várzeas dos trechos de baixa declividade, próximo das fozes dos rios urbanos, além de áreas de alta declividade e expansão na circunvizinhança dos habitacionais sociais $(\mathrm{COHAB})$, o que também combina com a supressão das áreas verdes não urbanizadas.

Assim, foram estabelecidas três grandes unidades de paisagem como os agrupamentos destes maiores valores de vulnerabilidade. A primeira unidade se trata das várzeas ocupadas do Rio Paratibe, como indicado no parágrafo anterior, este tipo de ocupação é corriqueiro na região metropolitana do Recife. Entretanto, se debruçando sobre a crise sanitária que o vírus desnudou, as variáveis mais preocupantes estão imbricadas com a disponibilidade e a relação que os moradores têm com os recursos hídricos. As infraestruturas (água e esgoto) inexistem nesta localidade, o que sugere também uma alta vulnerabilidade para as arboviroses, aumentando o grau de letalidade que o COVID-19 pode ocasionar. 


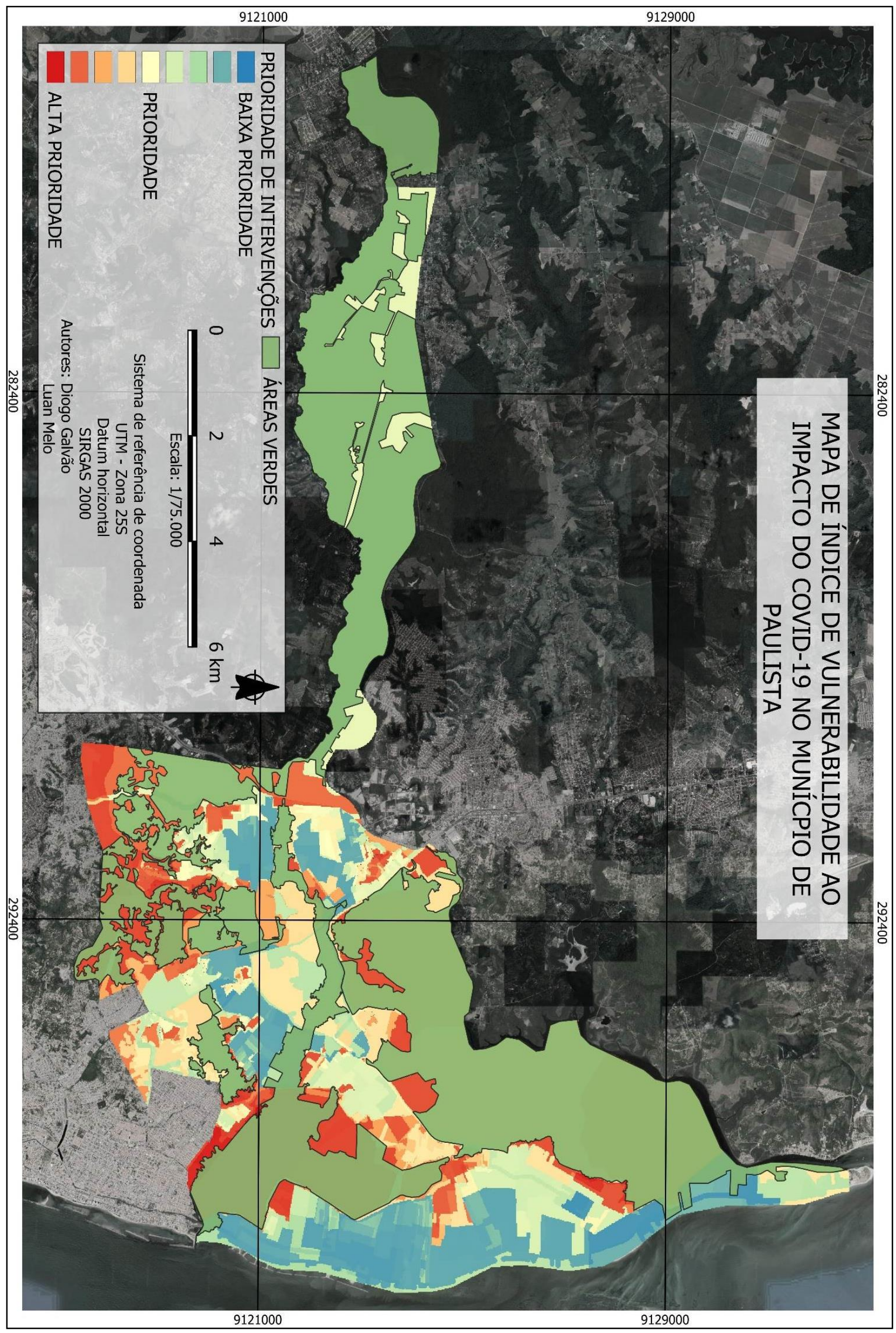

Revista Contexto Geográfico Maceló-AL V. 5. N.9 JulHO/2020

P. $31-44$

PÁGINA 42 
A segunda grande unidade de paisagem se estabelece nos setores Oeste do município, são áreas com declividade acentuada e uma densa ocupação unifamiliar. Apesar destas áreas de morro, diferentemente das áreas de várzea, apresentarem certa infraestrutura sanitária, principalmente no que tange a disponibilidade de água, os valores de vulnerabilidade estão ligados a existência do alto grau de risco de deslizamento. A utilização desta variável se deu pela preocupação de uma possível necessidade de retirada dos moradores em momentos de alta precipitação. Pois, até o presente momento não foi apresentado um plano emergencial que supra as demandas de isolamento social em caso de evacuação.

Por fim, a terceira unidade de paisagem está intimamente ligada a supressão vegetal em massa, este é um comportamento comum na expansão imobiliária das periferias das grandes cidades. A incapacidade de acompanhar o crescimento urbano pelo poder público, faz com que surjam novos aglomerados sem qualquer estrutura que os sirvam. São estes aspectos encontrados na bacia do Rio Poty, na porção nordeste do munípcio de Paulista e na faixa litorânea, no centro sul, no bairro do Janga, mais precisamente na comunidade do Tururu, sendo esta na bacia do rio Paratibe. Informações disponíveis quanto as estruturas de abastecimento d'água e esgotamento sanitário não possibilitam indicar que as comunidades recebam em sua totalidade estes serviços, além dos problemas de drenagem e o risco de enchentes.

Além dos atributos urbanos e ambientais, alguns de cunho social também são protagonistas quanto a identificação das áreas vulneráveis, como os valores percentuais das mães chefes de família e das famílias vulneráveis à pobreza dependente da renda de um idoso, fomentando o entendimento de que as famílias socialmente vulneráveis são aquelas que ocupam as áreas ambientalmente vulneráveis. Evidenciando a segregação espaço/social e assim, a necessidade urgente de intervenção diferenciada para essas comunidades, uma vez que sua configuração urbana e ambiental sugerem um alto grau de transmissibilidade, e somada a característica sociais que dificultam a possibilidade de isolamento, formam um cenário preocupante em "caso de" ou quando o vírus chegar.

\section{CONSIDERAÇÕES FINAIS}

É importante salientar que este é um produto inicial de uma parceria entre movimentos sociais que buscam monitorar e nortear as ações do poder público contra o coronavírus, principalmente nas periferias do município de Paulista. Tendo isto em mente, haverá necessidade de atualização, recomposição, recalibração e de revalidação sempre que houver a introdução de novos dados e variáveis.

A aplicação do método se confirmou muito promissora. Pois foi constatada a partir das análises dos movimentos sociais, comunidades já reconhecidamente vulneráveis. Entretanto, as variações destas vulnerabilidades se apresentam principalmente nos atributos urbanos e ambientais que aumentariam o impacto comunitário do COVID-19.

Foi fundamental para a construção do método a participação de profissionais das ciências propedêuticas, que se debruçavam sobre os problemas com distintos pontos de vista. Essa diversidade de visões culminou na elaboração da matriz de autovetores e nas hierarquias estabelecidas, fortalecendo o entendimento da vulnerabilidade multidisciplinar.

Entretanto, como todo método tem sua limitação, vale salientar dois aspectos que merecem constante reflexão para produtos que buscam uma classificação socioambiental. O primeiro deles está relacionado a ausência ou deficiência dos dados disponibilizados pelo poder público, fica clara a necessidade da produção de dados sociais de todas as esferas do poder, nacionalmente os dados oriundos do IBGE ou IPEA tem uma qualidade ímpar, entretanto uma defasagem temporal preocupante. Quando se investiga dados produzidos pelos municípios, fica ululante a ausência de planejamento para aquisição, processamento e divulgação dos mesmos. A cidade de Paulista é componente de uma das cinco maiores regiões metropolitanas do Brasil, 
entretanto houve grande dificuldade de conseguir dados oficiais, seja por burocracia ou inexistência de informações básicas.

Outro aspecto relacionado à limitação do método está voltado a dupla utilização de variáveis sociais, isto fica claro ao usar o índice de vulnerabilidade social do IPEA que é composto por um leque de atributos oriundos do IBGE, os quais alguns foram utilizados individualmente na composição da matriz. Apesar dessa duplicidade ser justificável principalmente quando o objetivo não é voltado apenas ao cunho social como é este mapeamento. É primordial ressaltar o cuidado que se deve ter na análise prévia dos dados e variáveis que serão utilizados para o mapeamento a partir do método AHP.

\section{REFERÊNCIAS}

ATLAS DA VULNERABILIDADE SOCIAL NOS MUNICÍPIOS BRASILEIROS / editores: Marco Aurélio Costa, Bárbara Oliveira Marguti. - Brasília : IPEA, 2015. Disponível: http://ivs.ipea.gov.br/images/publicacoes/Ivs/publicacao_atlas_ivs.pdf. Acessado em: abril, 2020

BRANDÃO, A. A. Conceitos e coisas: Robert Castel, a "desfiliação" e a pobreza urbana no Brasil. Emancipação, 2(1): 141-157, 2002.

CASTEL, R. As metamorfoses da questão social. Petrópolis, Vozes, 1998.

CENSO DEMOGRÁFICO 2010: características da população e dos domicílios: resultados do universo. In: IBGE. Sidra: sistema IBGE de recuperação automática. Rio de Janeiro, 2011a. Disponível em: <https://www.ibge.gov.br/estatisticas/downloads-estatisticas.html>. Acesso em: abril 2020.

MOSER, G. Psicologia ambiental. Estudos de Psicologia, 3(1), 121-130. 1998

OLIVEIRA, P C. Degradação ambiental em fragmento de Mata Atlântica: floresta urbana Mata do Janga em Paulista/PE. Dissertação (mestrado) - Universidade Federal de Pernambuco, CFCH Recife: 87p. 2015

PAULISTA. Plano Diretor da Cidade do Paulista. Secretaria de planejamento urbano/prefeitura de Paulista. 2013

PERNAMBUCO. Metrópole 2010 - Plano Diretor da Região Metropolitana do Recife. CONDEPE/FIDEM, Recife. 2010. Disponível: http://www2.condepefidem.pe.gov.br/web/condepefidem/apresentacao8. Acessado em: abril 2020.

SAATY, T. L. Método de análise hierárquica. São Paulo: McGrawHill Pub. Co: 367 p. 1991

How to Make a Decision: The Analytic Hierarchy Process. The Institute for Operations Research and the Management Sciences, Interfaces 24(6), pg. 19-43, USA, 1994.

SILVA, C.A.S. e NUNES, F.P. Mapeamento de vulnerabilidade ambiental utilizando o método AHP: uma análise integrada para suporte à decisão no município de Pacoti/CE. In Anais XIV Simpósio Brasileiro de Sensoriamento Remoto, Natal. P 5435-5442. 2009.

SILVA, D. M. R. Aplicação do Método AHP para Avaliação de Projetos Industriais Dissertação (Mestrado em Engenharia Industrial)-Pontifícia Universidade Católica do Rio de Janeiro, Rio de Janeiro: 128p. 2007. 